\title{
PCR utility over conventional tests for detection of Mycobacterium spp. in patients with mastitis and granulomatous lymphadenitis: Case series
}

\author{
José J. Márquez-Barajas, Manuel Solano-Genesta, Leonora Valdez-Rojas, Johana J. Garnica-Vázquez, \\ José F. Anaya-Gómez, Sergio A. Trujillo-Vega, Oscar Bañuelos-Robles, Guillermo E. Juárez-López, \\ Estefania N. Valdés-Peregrina, Cristina A. Luna-González, and Luis A. García-González
}

High Specialty Unit in Breast Cancer, Insituto Nacional de Oncología, Guadalajara, Jalisco, Mexico

\begin{abstract}
Objective: The present study aims to highlight the utility of quantitative polymerase chain reaction (qPCR) as a method for identifying typical and atypical mycobacterial infections in patients with mastitis and granulomatous lymphadenitis. Materials and methods: A total of five patients initially diagnosed with mastitis or granulomatous lymphadenitis based on their clinical characteristics in whom conventional tests were used as a diagnostic method were selected. Conclusion: The present study showed that the routine performance of qPCR for typical and atypical mycobacteria allows for improved diagnosis.
\end{abstract}

Keywords: Quantitative polymerase chain reaction. Mycobacterium spp. Granulomatous mastitis. Granulomatous lymphadenitis.

\section{Introduction}

Idiopathic granulomatous mastitis, also known as idiopathic lobular granulomatous mastitis, is a benign chronic inflammatory disease of the breast with an unknown etiology ${ }^{1}$. A definitive diagnosis is primarily established through histopathology. Accordingly, biopsies reveal a granuloma formation in combination with localized infiltration of multinucleated giant cells, epithelioid histiocytes, and plasma cells. The diagnosis and treatment of patients with granulomatous mastitis continues to be a challenge for physicians, considering the non-definitive results that can be obtained from ultrasound, mammography, and magnetic resonance imaging. This promotes a prolonged course of the disease with a significant impact on quality of life ${ }^{2}$.
Chronic granulomatous lymphadenitis is a distinct form of inflammatory immune response in which organized collections of epithelial macrophages form granulomas. In general, granulomatous inflammation occurs when the immune system fails to eliminate a foreign body and instead covers it with activated macrophages $^{3}$. The etiologies of axillary lymph node granulomas are similar to those of breast parenchyma granulomas, and patients generally exhibit tenderness, erythema, swelling, and abscess formation ${ }^{4}$.

Tuberculosis $(\mathrm{Tb})$ is a serious disease that continues to be a public health problem worldwide ${ }^{5}$. Mycobacterium tuberculosis remains the primary causative agent of Tb in developing and underdeveloped countries, with atypical mycobacteria rarely being isolated ${ }^{6}$. Although

\section{Correspondence:}

*Luis A. García-González

E-mail: luisgarcia.inv@ hotmail.com
Available online: $18-10-2021$

Date of reception: 01-12-2020

Date of acceptance: 11-05-202 DOI: 10.24875/RMU.20000086
Medicina Universitaria. 2021;23(3):89-94 www.medicinauniversitaria.org license (http://creativecommons.org/licenses/by-nc-nd/4.0/). 
the lungs continue to be the primary site of $\mathrm{Tb}$ infection, increasing reports of extra-pulmonary $\mathrm{Tb}$ have emerged worldwide, suggesting the potential for Tb to spread into various organs throughout the body ${ }^{5}$. Approximately $90 \%$ of atypical mycobacterial infections are located in the pulmonary system, followed by the lymph nodes, skin, soft tissues, bones, and less frequently in the central nervous system, ears, and breast? ${ }^{7}$.

Mycobacterial identification has traditionally been based on phenotypic characteristics such as growth rate, colony morphology and pigmentation, optimal growth temperature, and reactions as part of a battery of biochemical tests. Many of these tests require growth in solid media that are poorly reproducible and may take several weeks of incubation before species-level identification can be performed. An acid-fast bacilli (AFB) smear should be performed on all samples submitted for mycobacterial testing, except for blood samples, on which an AFB smear cannot be performed. Moreover, a Ziehl-Neelsen or Kinyoun stain is adequate for AFB smears confirming the presence of AFB in a culture. In most cases, cultures using a commercial broth system can return negative at 6 weeks ${ }^{8}$. Because of the above, there is a need for more effective diagnostic methods. One option is the application of the quantitative polymerase chain reaction (qPCR). The qPCR test is considered a high-cost study and, although it is usually performed in other conditions for the detection of $M$. tuberculosis, this is not a daily practice. In Mexico, conventional methods with the lower sensitivity and specificity are still used to detect both pulmonary and extra-pulmonary Mycobacterium spp, prolonging diagnosis time and increasing costs. Considering the continued diagnostic difficulties and treatment delays, the current study aims to demonstrate the utility of qPCR for expediting the diagnosis and treatment of granulomatous mastitis and lymphadenitis.

\section{Materials and methods}

The present study discusses the cases of five patients diagnosed with idiopathic mastitis and/or granulomatous adenitis who showed no response to treatment based mainly on high doses of steroids. After a multidisciplinary evaluation of the cases, qPCR tests for typical or atypical mycobacteria were performed based on a biopsy or paraffin-embedded tissue section, depending on the patient. GPCR tests were requested despite bacteriological cultures for $\mathrm{Tb}$ and Ziehl-Neelsen staining being negative in some cases.

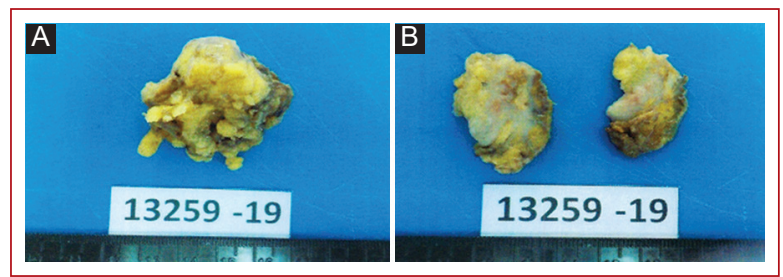

Figure 1. A: low lymph node section with a fragment of fatty tissue $(3.2 \times 3.0 \mathrm{~cm})$ and multiple light yellow semi-firm nodules measuring 1.0 to $2.5 \mathrm{~cm}$. B: tissue sections showed lymph nodes with an architecture altered by the presence of chronic inflammatory infiltration of lymphocytes, plasma cells, macrophages, and a few multinucleated Langhans-type giant cells, all surrounding areas of caseous necrosis. ZiehlNeelsen staining did not show bacilli, while findings of malignancy were not observed.

\section{Case 1}

A 31-year-old male patient with no prior history of Tb or other important background sought treatment for asthenia, adynamia, night fever for 2 weeks, and weight loss of $4 \mathrm{~kg}$ in 3 weeks. He also reported intense pain in his right armpit. A physical examination revealed palpable, slightly painful, 3-cm adenopathies at the axillary level. An ultrasound of the armpit revealed a 4-cm mass of purulent content, while a subsequent puncture culture did not reveal bacterial growth with a gram stain. Contrast-enhanced computed tomography of the chest and neck showed lymphadenopathies with an inflammatory appearance at cervical levels IA, IB, IIA, IIB, II, IV, VA, and BV.

Moreover, images showed smooth, well-defined edges, and a density similar to a muscle, with the largest lymphadenopathy $(7.5 \mathrm{~cm})$ located on the left IIA. A Quantiferon-TB Gold test returned positive for what was suspected to be nodal TB. Low dissection of the conglomerate lymph node on the right armpit was then performed, after which a diagnosis of granulomatous lymphadenitis negative for malignancy and Ziehl-Neelsen staining was established (Fig. 1). qPCR for typical and atypical mycobacteria revealed positive genotyping for Mycobacterium kansasii. After completing a treatment course comprising rifampicin, isoniazid, pyrazinamide, and ethambutol, the patient showed adequate resolution and remission of symptoms.

\section{Case 2}

A 69-year-old female patient with a history of Tb 32 years prior and infiltrating ductal adenocarcinoma of 
the right breast, for which she underwent a radical mastectomy, adjuvant chemotherapy, and hormone therapy, sought treatment for a palpable lymphadenopathy in the right armpit that was present for 4 weeks, which was associated with a probable recurrence of breast cancer. Physical examination revealed a $4.0 \times$ $3.5 \mathrm{~cm}$ soft, non-tender mass at the right axillary tail of the inner arm. Ultrasound revealed post-surgical-type changes consistent with BI-RADS 5. An ultrasound-guided Tru-cut biopsy revealed chronic granulomatous lymphadenitis with caseous necrosis and a Ziehl-Neelsen stain negative for bacilli. qPCR was performed for M. tuberculosis which was negative. However, due to the progression of the disease, another qPCR was requested a month later for atypical mycobacterium, which was positive for Mycobacterium abscessus. After completing a 6-month treatment course comprising ertapenem, levofloxacin, and clarithromycin, the patient exhibited complete response throughout follow-up.

\section{Case 3}

A 28-year-old female patient with no history of Tb or other important background sought treatment for pain in her left breast with a palpable mass present for 8 months beginning in April 2019. AFB revealed ductal ectasia, while an ultrasound of the left breast showed mastitis and abscess (BI-RADS 3). Abscess drainage was performed; however, recurrence was noted and managed with debridement and surgical cleaning on multiple occasions. Tissue biopsy confirmed granulomatous mastitis with negative Ziehl-Neelsen staining for bacilli. For this reason, the disease was established as idiopathic, and treatment with high doses of prednisone was initiated without success. qPCR for typical and atypical mycobacteria revealed positive genotyping for M. tuberculosis. The patient subsequently started on rifampicin, pyrazinamide, ethambutol, and isoniazid for 9 weeks, followed by supportive treatment for 4 months, with adequate results and resolution of injuries and symptoms.

\section{Case 4}

A 35-year-old female patient with no history of $\mathrm{Tb}$ sought treatment for asthenia, adynamia, diaphoresis (thrice), and lymphadenopathy on the left side of the neck that was present for 1 month. Excisional biopsy of the neck lymphadenopathy revealed mixed cellularity-type Hodgkin lymphoma (Fig. 2). The patient also

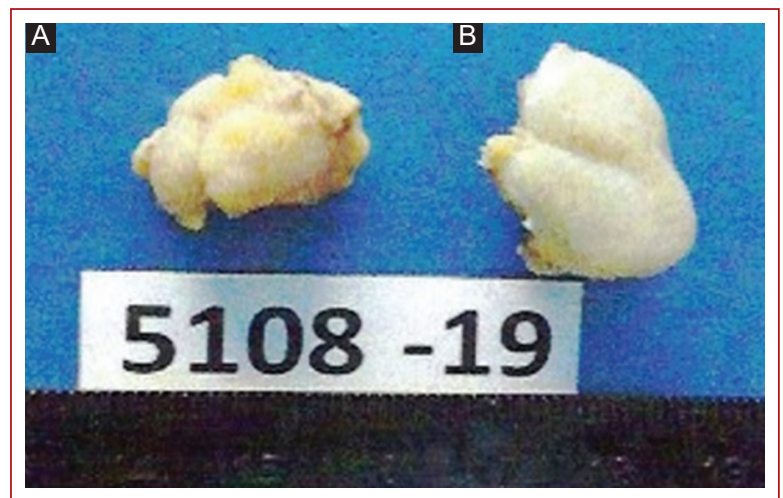

Figure 2. A: ganglion 1. Irregular, yellowish-brown tissue with a dimension of $1.8 \times 1.5 \times 1.4 \mathrm{~cm}$ from which two white and semi-firm nodules, measuring 1.0 and $1.5 \mathrm{~cm}$ at their greatest diameter, were dissected.

B: ganglion 2. White nodule previously sectioned during trans operative study, with a $2.5 \times 1.6 \mathrm{~cm}$ dimension and a smooth capsular surface. When cut, the nodule was light brown with a semi-firm consistency. Tissue sections of the lymph node showed a proliferation of large cells with clear cytoplasm, large nuclei, vesicular with prominent nucleoli, and some binucleated (ReedStemberg cells) and mononucleated (Hodgkin's cells) cells with a scattered distribution and surrounded by an inflammatory infiltrate comprising lymphocytes, plasma cells, eosinophils, and histiocytes.

underwent computed tomography, which suggested probable pneumonia. qPCR for typical and atypical mycobacteria revealed positive genotyping for $M$. $t u$ berculosis. After completing treatment, the patient showed adequate results and resolution of lesions and symptoms.

\section{Case 5}

A 47-year-old female patient with no history of $\mathrm{Tb}$ sought treatment for asthenia, adynamia, and nodulation in her right breast that was present for 6 months and nocturnal hyperthermia without diaphoresis. A nodular resection was performed; however, recurrence was noted. Physical examination of her right breast revealed a yellowish milky exudate and blood at the lesion site and two ulceration and induration sites with hyperthermia and pain on palpation. A bilateral mammary ultrasound revealed a heterogeneous fibroglandular-like echogenicity in the right breast and increased vascularity on Doppler ultrasound associated with ectatic peripheral ducts. Moreover, bilateral contrasted-enhanced magnetic resonance imaging showed data suggestive of breast abscesses with a fistula at the 


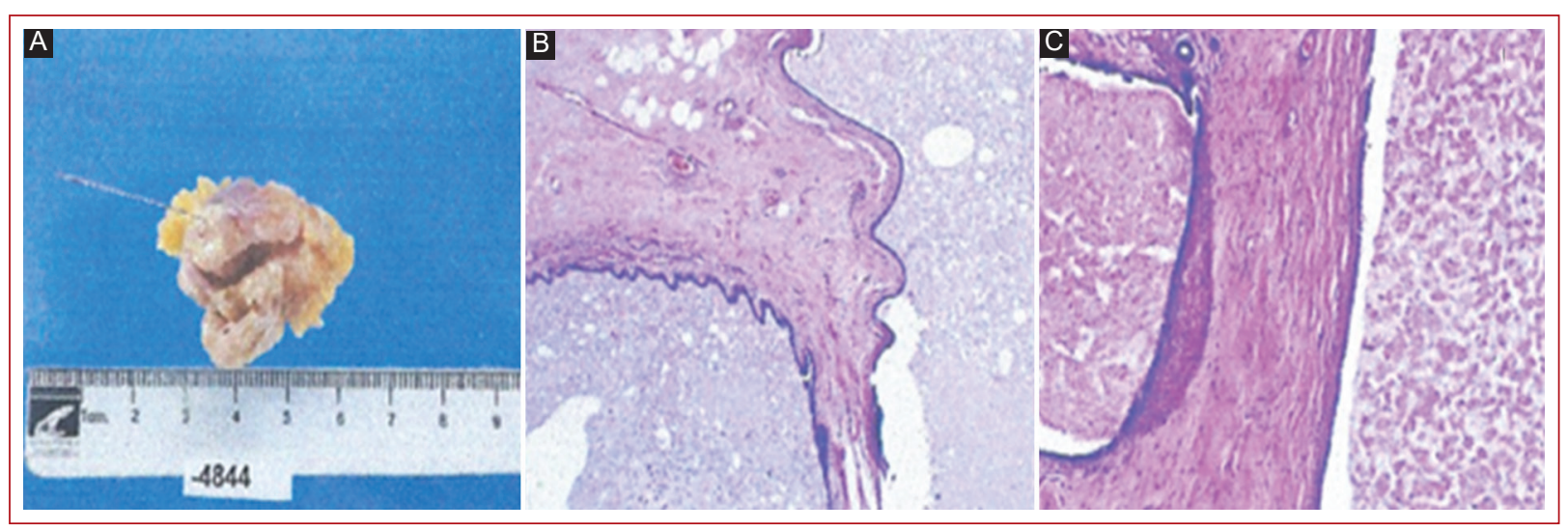

Figure 3. A: fresh trans operative histopathological study; the product of right mammary gland lesion resection $(3.4 \times 2.5 \times 2.3 \mathrm{~cm})$. B-C: histological sections stained with hematoxylin and eosin showed a mammary tissue with altered architecture due to various cysts and ducts with eosinophilic granular luminal secretion, few macrophages, double-row coating of polygonal cells, uniform without atypia with some luminal projections, and intact basement membrane, as well as dense fibroconnective stroma with periductal lymph histiocytic infiltrate, various mature acini, and congestive adipose tissue. Altogether, no data suggesting malignancy were noted.

ipsilateral areolar border (BI-RADS 4a). Accordingly, a diagnosis of granulomatous mastitis was established. qPCR for typical and atypical mycobacteria revealed positive genotyping for M. tuberculosis and Mycobacterium kansasii. The patient started and finished treatment with adequate results and resolution of injuries and symptoms (Fig. 3).

Table 1 shows additional information regarding the characteristics of the samples (biopsies) from which the qPCR test was performed and their results.

\section{Discussion}

Given the lack of defined clinical features, breast $\mathrm{Tb}$ has generally been misdiagnosed as another breast disease ${ }^{9}$. On clinical presentation, up to a third of all patients with granulomatous mastitis show abscess-like symptoms, such as pain, erythema, massive fluid accumulation on ultrasound, and reactive lymphadenopathy. Such patients may undergo puncture, drainage, or incision of the abscess depending on the size of the lesion. Aspiration can fail given that the abscess-like mass often has necrotic tissue at the center that makes the aspirate thick and difficult to remove. Typically, microbiological cultures return negative ${ }^{2}$.

From the clinical cases currently presented, in cases 1 and 5, qPCR was requested for typical and atypical mycobacteria, obtaining positivity for an atypical mycobacterium in both cases; however, case 5 was also positive for M. tuberculosis (typical mycobacterium). In contrast, in case 2 , in which qPCR was requested for typical mycobacteria, the result became negative. A month later, qPCR was requested again for atypical mycobacteria, resulting in a positive for atypical mycobacteria ( $M$. abscessus). Therefore, we believe that with nonspecific clinical data, suggestive of mastitis and granulomatous lymphadenitis, QPCR should be requested for typical and atypical mycobacteria.

Rapid diagnosis of $\mathrm{Tb}$ has been widely regarded as essential for treatment and transmission control. Although extra-pulmonary forms of Tb have low communicability, they tend to be more aggressive or generate sequelae that can significantly limit the patient's quality of life ${ }^{10}$. Early control of mycobacterial infections relies on rapid identification of complex nontuberculous and tuberculous mycobacterial infections from a clinical sample, which can reduce both morbidity and mortality by allowing the implementation of the most appropriate pharmacological treatment ${ }^{11}$.

Although rare, mastitis and granulomatous lymphadenitis are often diagnosed and treated as idiopathic diseases, given the negative results for Ziehl-Neelsen staining or bacteriological cultures. They usually present a torpid evolution, disease progression, and important cosmetic sequelae. Although a reliable and timely diagnosis is vital for disease detection, smear microscopy (developed more than 100 years ago), which detects disease through AFB observation, has remained the most commonly used diagnostic method. While smear microscopy does allow for a relatively quick diagnosis, it requires between 5000 and 10,000 bacilli per $\mathrm{mL}$ of sample. Moreover, given that smear microscopy 
Table 1. Sample's characteristics and mycobacteria detected

\begin{tabular}{|c|c|c|c|c|}
\hline Case & Sample type & Method & Genotyping of typical and atypical mycobacteria & Mycobacteria detected \\
\hline Case 1 & $\begin{array}{l}\text { Fresh from } \\
\text { Tissue. Low } \\
\text { lymph node } \\
\text { dissection }\end{array}$ & qPCR & $\begin{array}{l}\text { Mycobacterium szulgai. Mycobacterium abscessus, Mycobacterium } \\
\text { kansasii, Mycobacterium scrofolaceum, Mycobacterium simiae, } \\
\text { Mycobacterium peregrinum, Mycobacterium lentiflavium, } \\
\text { Mycobacterium intracellulare, Mycobacterium parascrofolaceum, } \\
\text { Mycobacterium malmoense, Mycobacterium fortuitum, } \\
\text { Mycobacterium phlei, Mycobacterium smegmatis, Mycobacterium } \\
\text { genavense, Mycobacterium avium, Mycobacterium bovis, } \\
\text { Mycobacterium heckeshornense, Mycobacterium marinum, } \\
\text { Mycobacterium xenopi, Mycobacterium bohemicum, } \\
\text { Mycobacterium haemophilum, Mycobacterium celatum, } \\
\text { Mycobacterium gordonae, Mycobacterium chelonae }\end{array}$ & Mycobacterium kansasii \\
\hline Case 2 & $\begin{array}{l}\text { Paraffin- } \\
\text { embedded } \\
\text { tissue. } \\
\text { Axillary node } \\
\text { biopsy }\end{array}$ & qPCR & $\begin{array}{l}\text { Mycobacterium szulgai. Mycobacterium abscessus, Mycobacterium } \\
\text { kansasii, Mycobacterium scrofolaceum, Mycobacterium simiae, } \\
\text { Mycobacterium peregrinum, Mycobacterium lentiflavium, } \\
\text { Mycobacterium intracellulare, Mycobacterium parascrofolaceum, } \\
\text { Mycobacterium malmoense, Mycobacterium fortuitum, } \\
\text { Mycobacterium phlei, Mycobacterium smegmatis, Mycobacterium } \\
\text { genavense, Mycobacterium avium, Mycobacterium bovis, } \\
\text { Mycobacterium heckeshornense, Mycobacterium marinum, } \\
\text { Mycobacterium xenopi, Mycobacterium bohemicum, } \\
\text { Mycobacterium haemophilum, Mycobacterium celatum, } \\
\text { Mycobacterium gordonae, Mycobacterium chelonae }\end{array}$ & $\begin{array}{l}\text { Mycobacterium } \\
\text { abcsessus }\end{array}$ \\
\hline Case 3 & $\begin{array}{l}\text { Biopsy } \\
\text { tissue }\end{array}$ & qPCR & $\begin{array}{l}\text { Mycobacterium avium, Mycobacterium intracelullare, } \\
\text { Mycobacterium kansasii, Mycobacterium malmoense, } \\
\text { Mycobacterium xenopi, Mycobacterium szulgai, Mycobacterium } \\
\text { mucogenicum, Mycobacterium scrofulaceum, Mycobacterium } \\
\text { haemophilum, Mycobacterium smegmatis, Mycobacterium simiae, } \\
\text { Mycobacterium celatum, Mycobacterium bovis, Mycobacterium } \\
\text { africanum }\end{array}$ & $\begin{array}{l}\text { Mycobacterium } \\
\text { tuberculosis }\end{array}$ \\
\hline Case 4 & $\begin{array}{l}\text { Neck lymph } \\
\text { node }\end{array}$ & qPCR & Mycobacterium tuberculosis & $\begin{array}{l}\text { Mycobacterium } \\
\text { tuberculosis }\end{array}$ \\
\hline Case 5 & $\begin{array}{l}\text { Paraffin- } \\
\text { embedded } \\
\text { tissue }\end{array}$ & $\begin{array}{l}\text { qPCR and } \\
\text { hybridization } \\
\text { to } \\
\text { microarrays }\end{array}$ & $\begin{array}{l}\text { Mycobacterium szulgai. Mycobacterium abscessus, Mycobacterium } \\
\text { kansasii, Mycobacterium scrofulaceum, Mycobacterium simiae, } \\
\text { Mycobacterium peregrinum, Mycobacterium lentiflavium, } \\
\text { Mycobacterium intracellulare, Mycobacterium parascrofolaceum, } \\
\text { Mycobacterium malmoense, Mycobacterium fortuitum, } \\
\text { Mycobacterium phlei, Mycobacterium smegmatis, Mycobacterium } \\
\text { genavense, Mycobacterium avium, Mycobacterium bovis, } \\
\text { Mycobacterium heckeshornense, Mycobacterium marinum, } \\
\text { Mycobacterium xenopi, Mycobacterium bohemicum, } \\
\text { Mycobacterium haemophilum, Mycobacterium celatum, } \\
\text { Mycobacterium gordonae, Mycobacterium chelonae }\end{array}$ & $\begin{array}{l}\text { Mycobacterium } \\
\text { tuberculosis and } \\
\text { Mycobacterium kansasii }\end{array}$ \\
\hline
\end{tabular}

qPCR: quantitative polymerase chain reaction.

has a sensitivity between 5 and $20 \%$ for extra-pulmonary samples, the possibility of obtaining a negative smear when no pulmonary symptoms are present should be considered ${ }^{12}$.

At present, nucleic acid-based technologies have been used to detect tuberculous mycobacteria with very high sensitivity and specificity, overcoming some of the problems associated with classical standard laboratory methods. Although rapid and cost-effective, microscopic examination of AFB has low sensitivity and specificity, particularly in paucibacillary specimens and cultures. Despite being considered the gold standard due to its high sensitivity, the microscopic examination requires several weeks to produce a result. It has a lower sensitivity for the detection of extra-pulmonary $\mathrm{Tb}^{5}$. Notably, the use of qPCR for the identification of M. tuberculosis has shown excellent results, with a sensitivity varying from 65 to $100 \%$ and a specificity of $98 \%$, as well as a decrease in the number of days before treatment initiation (approximately 3-5 days) ${ }^{13}$.

Current traditional methods lack sensitivity and specificity, and a rapid diagnosis of $\mathrm{Tb}$ is essential to initiate adequate treatment. However, in many cases, the performance of QPCR is postponed or not considered due 
to the costs that it may present for patients. Still, with the cases presented, we can realize the usefulness of performing qPCR for both typical and atypical mycobacteria to get an accurate diagnosis and start treatment early.

\section{Conclusions}

The present study shows that the routine performance of qPCR for typical and atypical mycobacteria allows for improved diagnosis, increased diagnosis of infectious cases according to the different types of mycobacteria, increased treatment specificity, and adequate progression and treatment of patients.

\section{Conflicts of interest}

The authors declare no conflicts of interest.

\section{Funding}

The authors declare that they have not received financial support from any organization for this study/ presentation.

\section{Ethical disclosures}

Protection of human and animal subjects. The authors declare that the procedures followed were in accordance with the regulations of the relevant clinical research ethics committee and with those of the Code of Ethics of the World Medical Association (Declaration of Helsinki).

Confidentiality of data. The authors declare that they have followed the protocols of their work center on the publication of patient data.
Right to privacy and informed consent. The authors have obtained the written informed consent of the patients or subjects mentioned in the article. The corresponding author is in possession of this document.

\section{References}

1. Maione C, Palumbo VD, Maffongelli A, Damiano G, Buscemi S, Spinelli G, et al. Diagnostic techniques and multidisciplinary approach in idiopathic granulomatous mastitis: a revision of the literature. Acta Biomed. 2019;90:11-5.

2. Wolfrum A, Kümmel S, Theuerkauf I, Pelz E, Reinisch M. Granulomatous mastitis: a therapeutic and diagnostic challenge. Breast Care (Basel). 2018;13:413-8.

3. Miranda RN, Khoury JD, Medeiros LJ. Chronic granulomatous lymphadenitis. In: Atlas of Lymph Node Pathology. Atlas of Anatomic Pathology. New York: Springer; 2013. p. 23-4.

4. Illman JE, Terra SB, Clapp AJ, Hunt KN, Fazzio RT, Shah SS, et al. Granulomatous diseases of the breast and axilla: radiological findings with pathological correlation. Insights Imaging. 2018;9:59-71.

5. Khosravi AD, Alami A, Meghdadi H, Hosseini AA. Identification of Mycobacterium tuberculosis in clinical specimens of patients suspected of having extra-pulmonary tuberculosis by application of nested PCR on five different genes. Front Cell Infect Microbiol. 2017;7:3.

6. Gupta P. Difficulties in managing lymph node tuberculosis. Lung India. 2004;21:50-3

7. Magaña-Leal JA, Bustos-Saldaña R, Torres-Baranda R, Cárdenas-Cuevas AL, Quiñonez-Cibrián E, Serrano-Gómez MV. Micobacterias atípicas de secreción mamaria identificadas en el primer nivel de atención reporte de seis casos. Atención Fam. 2017;24:40-6.

8. Forbes BA, Hall GS, Miller MB, Novak SM, Rowlinson MC, Salfinger M, et. al. Practice guidelines for clinical microbiology laboratories: mycobacteria. Clin Microbiol Rev. 2018;31:e00038-17.

9. Li Q, Huang YX, Yang Q, Dong YJ, Gao MQ, Ma LP. Case report: primary tuberculosis of the bilateral breast. Am J Trop Med Hyg. 2017; 97:1717-9.

10. Peñata A, Salazar R, Castaño T, Bustamante J, Ospina S. Diagnóstico molecular de tuberculosis extrapulmonar y sensibilidad a rifampicina con un método automatizado en tiempo real. Biomédica. 2016; 36:78-89.

11. Baldwin SL, Larsen SE, Ordway D, Cassell G, Coler RN. The complexities and challenges of preventing and treating nontuberculous mycobacterial diseases. PLoS Negl Trop Dis. 2019;13:e0007083.

12. Palacios-Marmolejo $A$, de Luna-Ramírez $G$, Ornelas-Perea $M$, Herrera-Leandro DA, Ortiz-Palos M, Silva-Menchaca JJ. Diagnóstico de tuberculosis extrapulmonar por cultivo. Neumol Cir Torax. 2017;76:84-90.

13. García-Elorriaga G, Gracida-Osorno C, Carrillo-Montes G, González-Bonilla $C$. Clinical usefulness of the nested polymerase chain reaction in the diagnosis of extrapulmonary tuberculosis. Salud Pública Mex. 2009;51:240-5. 